\title{
Aportes teóricos para el tratamiento del discurso mediático en la educación secundaria*
}

MARÍA BELÉN ROMANO*

Recepción: 30 de noviembre de 2017

Aprobación: 20 de marzo de 2018

Forma de citar este artículo: Belén M. (2018). Aportes teóricos para el tratamiento del discurso mediático en la educación secundaria. Cuadernos de Lingüística Hispánica, (32), 131-151.

* Artículo de reflexión derivado de mi investigación postdoctoral titulada "El discurso mediático en la Educación Secundaria: modos de abordaje, problemas y desafíos".

** Doctora en Letras (orientación Lingüística) por la Universidad Nacional de Tucumán, Argentina. Docente de la Facultad de Filosofía y Letras de la misma universidad e investigadora del Instituto de Investigaciones del Lenguaje y la Cultura (INVELEC). Becaria postdoctoral del CONICET. Correo electrónico: mbelenromano@hotmail.com 


\section{Resumen}

Desde sus orígenes, la relación entre educación y medios de comunicación ha sido compleja. En los últimos años, esta complejidad se ha incrementado debido al surgimiento de nuevos modos de conocimiento que desafían modelos pedagógicos tradicionales y que exigen tener en cuenta nuevos códigos y canales de comunicación. En este artículo exponemos y desarrollamos conceptos básicos para abordar la problemática de la incorporación del discurso mediático en la escuela secundaria, entre los que se destacan el de educación en medios y el de competencia mediática. Presentamos luego una propuesta, de carácter general, para guiar su enseñanza. Esta propuesta se basa en el marco teórico-metodológico del análisis crítico del discurso —específicamente en las tres dimensiones sistematizadas por Fairclough (1995) de práctica textual, discursiva y social一, en los enfoques críticos en torno al discurso mediático y en las concepciones acerca de educación en medios, competencia mediática y literacidad crítica. Asimismo, considera algunos resultados de encuestas aplicadas a estudiantes y docentes en el año 2016. El propósito último es contribuir al debate, la reflexión y la acción pedagógica para posibilitar la formación de sujetos capaces de comprender y producir mensajes mediáticos desde una mirada crítica, participativa y creativa.

Palabras clave: educación en medios, competencia mediática, literacidad crítica, análisis crítico del discurso, propuesta didáctica.

\section{Theoretical Contributions for the Approach of Media Discourse in High School}

\section{Abstract}

Since its origins, the relationship between education and mass media has been complex. In recent years, this complexity has increased due to the emergence of new modes of knowledge that challenge traditional pedagogical models and that require taking into account new codes and communication channels. In this article we expose and develop basic concepts to address the problem of the incorporation of media discourse in high school, among which stand out media education and media competence. We present then a general proposal, to guide its teaching. This proposal is based on the theoretical-methodological framework of the critical analysis of discourse -specifically in the three dimensions systematized by Fairclough (1995) of textual, discursive and social practice-, in the critical approaches on the media discourse and in the conceptions about of media education, media competence and critical literacy. It also considers some results of surveys applied to students and teachers in 2016. The ultimate purpose is to contribute to debate, reflection 
and pedagogical action to enable the training of subjects capable of understanding and producing media messages from a critical, participatory and creative perspective.

Keywords: media education, media competence, critical literacy, critical analysis of discourse, didactic proposal.

\section{Apports théoriques pour le traitement du discours médiatique dans l'éducation secondaire}

\section{Résumé}

Depuis ses origines, le rapport entre l'éducation et les médias a été complexe. Les dernières années, cette complexité a augmenté dû à l'apparition de nouvelles façons de connaissance qui défient des modèles pédagogiques traditionnels et qui exigent tenir compte de nouveaux codes et voies de communication. Dans cet article, nous exposons et développons des concepts de base, pour aborder la problématique de l'intégration du discours médiatique dans l'école secondaire, notamment celui de l'éducation aux médias et celui de la compétence médiatique. Ensuite, nous présentons une proposition, de caractère général, pour guider son enseignement. Cette proposition se fonde sur le cadre théorique-méthodologique de l'analyse critique du discours — spécifiquement sur les trois dimensions systématisées par Fairclough (1995) de pratique textuelle, discursive et sociale-, sur les approches critiques autour du discours médiatique et sur les conceptions concernant l'éducation aux médias, compétence médiatique et littératie critique. Notre proposition considère également quelques résultats des enquêtes réalisées auprès des étudiants et des enseignants en 2016. Le but final est celui de contribuer au débat, la réflexion et l'action pédagogique, pour rendre possible la formation des individus capables de comprendre et de produire des messages médiatiques à partir d0un regard critique, participatif et créatif.

Mots clés: éducation aux médias, compétence médiatique, littératie critique, analyse du discours, proposition didactique.

\section{Contribuições teóricas para a abordagem (Ou Tratamento) Do Discurso de mídia no ensino secundário}

\section{Resumo}

Desde suas origens, a relação entre educação e mídia tem sido complexa. Nos últimos anos, essa complexidade aumentou devido ao surgimento de novos modos de conhecimento que desafiam os modelos pedagógicos tradicionais e exigem a consideração de novos códigos e canais de comunicação. Neste artigo expomos e desenvolvemos conceitos 
básicos para abordar o problema da incorporação do discurso midiático no ensino médio, dentre os quais se destacam a educação para a mídia e a competência midiática. Apresentamos então uma proposta, de natureza geral, para guiar seu ensino. Essa proposta baseia-se no referencial teórico-metodológico da análise crítica do discurso - especificamente nas três dimensões sistematizadas por Fairclough (1995) de prática textual, discursiva e social -, nas abordagens críticas em torno do discurso midiático e nas concepções sobre educação para da mídia, a literacia mediática e letramento crítico. Também considera alguns resultados de pesquisas aplicadas a alunos e professores em 2016. 0 objetivo final é contribuir para o debate, a reflexão e a ação pedagógica para possibilitar a capacitação de sujeitos capazes de compreender e produzir mensagens midiáticas a partir de uma perspectiva crítica e participativa e criativo.

Palavras-chave: educação midiática, competência midiática, letramento crítico, análise crítica do discurso, proposta didática. 


\section{Introducción}

Ya no se discute la importancia del papel que tienen los medios masivos de comunicación en las sociedades actuales. La llamada sociedad de la información, donde las nuevas tecnologías de la información y la comunicación se hacen presentes cada vez con mayor fuerza, se ve bombardeada por mensajes y representaciones de mundo que llegan desde múltiples direcciones y a través de distintos canales. Tampoco se cuestiona el surgimiento de modos de conocimiento que exigen nuevas competencias en los sujetos. Esta atmósfera de cambios vertiginosos y de nuevas exigencias desafía a la escuela a repensar los procesos de enseñanza-aprendizaje tradicionales. En este sentido, uno de los ejes que deben discutirse se vincula a la relación entre educación y medios de comunicación que, si bien atravesó etapas de rupturas y otras de acercamientos, sigue generando diversos interrogantes.

Teniendo en cuenta este contexto, el objetivo del presente trabajo es presentar algunos conceptos que consideramos fundamentales para conformar un marco teórico que permita un tratamiento del vínculo educación/medios de manera significativa, entre los cuales se destaca el de educación en medios (Buckingham, 2005) y competencia mediática (Ferrés \& Piscitelli, 2012). Asimismo, y a partir de estos conceptos y de resultados de encuestas que aplicamos a estudiantes y docentes para conocer la visión que defienden acerca de esta problemática, buscamos brindar algunas pistas y proponer estrategias para trabajar con el discurso mediático en la educación secundaria. Con este propósito, desarrollamos una propuesta teórico-metodológica de carácter general, que aspira a funcionar como orientadora del tratamiento de los medios en el aula. La propuesta se sostiene en el marco teórico de la educación mediática y de la lectura y escritura crítica de medios (Alvermann \& Hagood, 2000). Considera también los aportes teórico-metodológicos del análisis crítico del discurso (Van Dijk, 2003; Fairclough, 2008). Por último, dentro de esta perspectiva multidisciplinaria y teniendo en cuenta la característica dialógica y la naturaleza interactiva y argumentativa de los nuevos géneros mediáticos, nos basamos en algunas nociones provenientes de la dimensión retórica de la argumentación (Perelman \& Olbrechts-Tyteca, 1994).

\section{Marco teórico}

\subsection{Acerca de educación en medios, literacidad crítica y competencia mediática}

En sociedades multiculturales donde las nuevas tecnologías de la información y la comunicación se hacen presentes cada vez con mayor fuerza, y los mensajes y represen- 
taciones de mundo llegan desde múltiples direcciones y a través de distintos canales, se plantean nuevas demandas y exigencias y se resignifica el papel de muchos actores sociales. Entre ellos cobran un rol destacado los medios masivos de comunicación como actores estratégicos del juego político y como creadores de representaciones de mundo enmarcadas en determinados posicionamientos ideológicos. A esta ubicuidad y relevancia del discurso mediático para la comprensión de lo social, se suman los nuevos modos de conocimiento y de circulación de ese conocimiento. Los saberes considerados válidos se han descentrado, han dejado de ser patrimonio absoluto de la institución escolar y han comenzado a circular en otras esferas que tienen una fuerte presencia en la vida de los jóvenes como lo es la de los medios de comunicación; asimismo, se han difuminado o borrado las fronteras que separaban los conocimientos académicos del saber común (Martín, 2003).

Así es como el rol de los medios de comunicación en las sociedades contemporáneas ha adquirido una importancia incuestionable. No obstante, fuertes debates se generan cuando se piensa en sus funciones y efectos. Es innegable que la mayor parte de los relatos que forman nuestro conocimiento sobre el mundo se originan en los discursos mediáticos. En este contexto surgen las preguntas acerca de las relaciones de la ciudadanía con estos actores sociales, relaciones que se vuelven más complejas cuando pensamos en la franja etaria de jóvenes y adolescentes quienes experimentan contactos permanentes con los discursos que provienen tanto de los medios tradicionales, como de las nuevas tecnologías de la información y la comunicación (TIC). En relación con esto, existe un nuevo desafío que debe afrontar el sistema educativo: formar ciudadanos competentes que puedan acceder y utilizar la heterogeneidad de discursos que circulan en el ámbito público. En este marco, educar significa capacitar a los ciudadanos para que puedan organizar su propia formación, es decir, para que puedan gestionar los conocimientos con el fin de aplicarlos a un determinado propósito (De Fontcuberta, 2003).

Son numerosas las investigaciones que han contribuido a definir, especificar, diferenciar y delimitar el campo de estudio referido a la educación y su relación con los medios de comunicación (Masterman, 1993; Buckingham, 2005; Pérez, 2005; De Fontcuberta \& Guerrero, 2007; Morduchowicz, 2009; Ferrés \& Piscitelli, 2012). Siguiendo a Buckingham (2003), definimos educación en medios como el proceso de enseñanza-aprendizaje sobre los medios, o bien, procesos de alfabetización mediática que promueven la construcción de saberes críticos en torno a los productos mediáticos (Wilson, Grizzle, Tuazon, Akyempong \& Cheung, 2011). En tal sentido, la educación en medios no buscará la mera transmisión de conocimientos sobre las tecnologías y los modos de utilizarlas, sino crear las condiciones de una relación con el saber que favorezca la emergencia del espíritu crítico. La educación en medios busca entender y analizar la manera en que los medios repre- 
sentan la realidad y el modo en que las audiencias incorporan y resignifican los mensajes (Gálvez, 2005). Como podemos observar, su fundamento radica en el entendimiento de los mensajes de los medios como construcciones, no como simples reflejos de la realidad.

Desde esta perspectiva, la preocupación de muchos investigadores se ha orientado hacia el ámbito de las nuevas tecnologías de la información y la comunicación. En este sentido, algunos trabajos teorizan sobre los modos en que se interpretan las TIC en el ámbito educativo. Hay casos en que se las comprende como simples herramientas 0 instrumentos que permiten acceder de forma fácil al conocimiento; en otros, se acentúa su dimensión revolucionaria, no solo desde el punto de vista instrumental sino también desde el punto de vista cultural y simbólico (Lankshear \& Knobel, 2009; Martín, 2009; Dussel, 2011). Otros describen la situación de diferentes países en cuanto a las políticas públicas generadas en torno a las nuevas tecnologías, analizan su modo de inserción en el campo educativo y presentan evaluaciones parciales de su impacto (Sunkel \& Truco, 2014; Grasso, Pagola \& Zanotti, 2017). También podemos nombrar investigaciones que reflexionan acerca de las percepciones del profesorado sobre el potencial de las TIC como favorecedoras del aprendizaje (Román \& Murillo, 2014; Vacchieri, 2013; Tirado \& Aguaded, 2014). Con respecto a los estudios que se ocupan de explorar y analizar propuestas didácticas que orienten "buenas prácticas" pedagógicas, si bien han cobrado auge en los últimos años, aún son incipientes, especialmente los que se refieren al nivel medio (Guerrero \& Kalman, 2010; Manghi, 2011; Serna, J. \& Díaz, 2014). Además existen investigaciones que hacen su aporte al campo describiendo las características de los nuevos géneros mediáticos surgidos a partir de los medios digitales y de las TIC, como lo son el chat, los mensajes de textos, los comentarios digitales, entre otros (Pujolá et al., 2009; Sal, 2013; Romano, 2015; Beltrán, 2017). A su vez, para referirse a las transformaciones de las prácticas de lectura y escritura, a los nuevos escenarios donde se desarrollan y a las nuevas dinámicas y formas que adquieren en la era digital (Martín, 2009; Rowsell \& Walsh, 2015) han surgido, en las últimas décadas, trabajos que reflexionan sobre su especificidad en relación con el discurso de los medios y cuyo eje vertebrador es la sistematización del concepto general de literacidad mediática crítica (Luke, 2004; Alvermann \& Hagood, 2000; García, Seglem $\&$ Share, 2013). Este concepto amplía y profundiza la noción de lectura crítica (Avendaño, 2016), o bien, de literacidad crítica (Cassany \& Castellá, 2010) que enfatiza el componente social y contextual de la lectura y la escritura, para incluir diferentes formas de comunicación masiva, de cultura popular y de nuevas tecnologías y para analizar críticamente las relaciones entre los medios y las audiencias, la información y el poder.

Fuertemente vinculado a los conceptos de educación en medios y de literacidad crítica, ha cobrado visibilidad la noción de competencia mediática (García, 2010; Pérez 
\& Delgado, 2012; Ferrés \& Piscitelli, 2012). Ferrés y Piscitelli (2012) la definen como el dominio de conocimientos, estrategias y actitudes relacionadas con seis dimensiones básicas: lenguajes, tecnología, procesos de interacción, de producción y difusión, ideología y valores, estética. Los autores especifican cuáles son los indicadores de cada dimensión teniendo en cuenta dos ámbitos: el de análisis, es decir, ámbito de participación de los sujetos que reciben mensajes e interaccionan con ellos; y el de la expresión, es decir, espacio donde los sujetos producen mensajes propios.

La primera dimensión, la de los "lenguajes", se entiende como la capacidad de interpretar y valorar diversos códigos de representación y su función dentro del mensaje así como la capacidad de expresarse mediante una amplia gama de sistemas de representación y de significación. La dimensión "tecnología" remite a la capacidad de comprender el papel de las tecnologías de la información y la comunicación y sus posibles efectos y manejar las innovaciones tecnológicas teniendo en cuenta entornos multimodales. En cuanto a la dimensión "procesos de interacción", se relaciona con el conocimiento de la importancia del factor contextual, con la capacidad de apreciar y valorar mensajes provenientes de otras culturas, analizar los efectos de sensaciones y emociones e interactuar y trabajar colaborativamente en entornos plurales y multiculturales. Los "procesos de producción y difusión" refieren a la identificación de las diferencias entre producciones individuales, colectivas, corporativas y la capacidad de producir información a través de medios tradicionales y redes sociales. La dimensión "ideología y valores" se relaciona con la capacidad para develar ideologías subyacentes que sustentan las representaciones mediáticas de la realidad y, a su vez, con la posibilidad de elaborar mensajes que cuestionen o subviertan representaciones hegemónicas reflejando una actitud de compromiso social y cultural. Por último, la dimensión "estética" remite, entre otros indicadores, a la capacidad para identificar categorías estéticas y producir mensajes creativos que potencien la sensibilidad estética y la innovación.

\subsection{Análisis crítico del discurso y dimensión retórica del discurso mediático}

De acuerdo con lo desarrollado hasta aquí, consideramos que, por sus fundamentos, uno de los marcos teórico-metodológicos más adecuados para abordar el estudio del discurso mediático es el análisis crítico del discurso (ACD). Según Van Dijk (2003), el ACD no es un método ya establecido de análisis, sino una perspectiva o actitud crítica que se ocupa de problemas sociales. Estudia las relaciones entre lenguaje, poder e ideología, es decir, analiza cómo se manifiestan a través del lenguaje las relaciones de dominación, poder y control. Se interesa por cómo los grupos o las instituciones dominantes crean y mantienen la desigualdad social por medio del lenguaje. Los analistas críticos consideran 
que la descripción y el análisis de los discursos deben hacerse desde una pluralidad de enfoques para ofrecer una visión completa y adecuada del objeto de estudio. En este sentido es un análisis multidisciplinario porque reúne aportaciones de distintas ciencias.

Para esta perspectiva de análisis, el discurso es una práctica social inmersa dentro de otras prácticas sociales con las cuales interacciona (Fairclough \& Wodak 2000; Fairclough, 2008). Esto significa que no defiende una relación determinista entre el discurso y lo social; por el contrario, define esta relación como dialéctica: todo acontecimiento discursivo se halla situado en un tiempo y espacio particular, en una situación social determinada y debe ser interpretado en virtud de las características propias de ese tiempo y espacio. Las situaciones, instituciones y estructuras sociales "moldean" los discursos. Pero, a su vez, el discurso también constituye lo social, contribuye a reproducir las relaciones desiguales que estructuran la sociedad o bien a transformarlas o subvertirlas (Fairclogh \& Wodak, 2000).

Es claro que toda producción de sentido está atravesada por las nociones de poder e ideología. Sin embargo, la mayoría de las veces, la influencia de estas nociones en dicha producción aparece enmascarada. La tarea del ACD es develar las complejas relaciones que se establecen entre las estructuras de poder, las ideologías y los discursos, o sea, desmitificar los discursos mediante el descifrado de las ideologías (Fairclough \& Wodak, 2000; Wodak, 2003; Van Dijk, 1999a, 2003). En este sentido, muchas de las investigaciones basadas en esta perspectiva se interesaron por el discurso político y mediático (Hernández, 2014; Álvarez \& Suárez, 2016). Especialmente los medios masivos de comunicación fueron y son un espacio destacado para el análisis y la reflexión de las formas de ejercicio del poder simbólico y de las estrategias retóricas desplegadas.

Tanto medios tradicionales como emergentes tienen por objetivo el logro de una comunicación eficaz que "afecta la actividad productiva del orador, la actividad interpretativa del oyente y las relaciones de adecuación entre el discurso, orador, oyente y contexto" (Berlanga, 2013, p. 43). La "retoricidad del lenguaje" (Albaladejo, 2007) adquiere relevancia en la sociedad de la información, época de la convergencia mediática y cultural donde como lectores, espectadores, consumidores o bien productores y participantes activos de los relatos, contamos con diversas posibilidades para el logro de nuestro objetivo comunicativo. Buscamos que el receptor reaccione de alguna manera, ya sea que adhiera a nuestra postura o que la cuestione. En este punto destacamos los aportes de Perelman y Olbrechts-Tyteca (1994) para la comprensión de la dimensión argumentativa del discurso mediático. Estos autores revitalizan los estudios retóricos y conceden gran importancia al papel del auditorio definido como "el conjunto de aquellos en quienes el orador quiere 
influir con su argumentación" (1994, p. 55). El orador debe tener en cuenta los condicionamientos del auditorio para buscar persuadirlo. Desde este marco, la argumentación se halla situada y, por lo tanto, la validez de un argumento descansa, no en la noción de verdad, sino en elementos relacionados con la cualidad situacional de toda argumentación.

Es importante subrayar que, tanto para abordar textos tradicionales como multimodales (Kress \& Van Leeuwen, 2001), la capacidad para resolver el problema retórico (Flower \& Hayes, 1981) es fundamental. La realización de todo producto comunicativo debe contemplar tres elementos que conforman la situación retórica: la audiencia o destinatarios, el tópico o tema y el propósito que se persigue de acuerdo con las intenciones del productor.

\section{Propuesta didáctica}

\subsection{Algunas pistas teórico-metodológicas}

Para desarrollar nuestra propuesta de carácter general y flexible, que aspiramos pueda servir de guía para el tratamiento del discurso mediático en la escuela secundaria, hemos tenido en cuenta los aportes teóricos expuestos en apartados anteriores y algunos resultados de encuestas que realizamos a estudiantes y docentes en el año $2016^{1}$. En esta oportunidad haremos una breve referencia a algunas conclusiones a las que arribamos luego de analizar los datos, y que consideramos importantes para diseñar la propuesta didáctica ${ }^{2}$.

Con respecto a la visión de los estudiantes, sorprende que un elevado porcentaje de egresados, un $44 \%$, dicen no haber trabajado con los medios durante su trayecto por la escuela secundaria. Los que contestaron afirmativamente (56\%) expresaron haberse relacionado, en mayor medida, con géneros tradicionales y lo hicieron a partir de prácticas que privilegiaban el aprendizaje a través de los medios. El mayor porcentaje estuvo conformado por noticias, entrevistas, historietas, publicidades, notas de opinión y crónicas. Mientras que aquellos que surgieron a partir del avance tecnológico (facebook, chat, foros, videojuegos, etc.) están representados por un porcentaje bastante inferior. Asimismo, cuando se indagó acerca de cómo se utilizó el discurso mediático en las clases, predominó

1 En relación con la encuesta realizada a los estudiantes, la muestra estuvo formada por 180 alumnos de primer año de una universidad pública, cuyas edades oscilaban entre los 18 y 25 años, egresados del secundario en el periodo 2010-2015, de instituciones públicas y privadas de la provincia de Tucumán, Argentina. En cuanto a los docentes, el instrumento fue completado por 170 colegas también pertenecientes a instituciones públicas y privadas de la provincia.

2 Un trabajo anterior (Romano, 2017) da cuenta con detenimiento de los resultados de la encuesta aplicada a los alumnos. En esta etapa de la investigación estamos elaborando un informe con los datos obtenidos a partir de las respuestas de los docentes. 
la respuesta que lo asimilaba a "medio de información para estudiar un tema específico de una determinada materia".

Los resultados de las encuestas realizadas a los docentes reafirman estas conclusiones. En relación con el modo de tratamiento de los medios, su utilización como "fuente de información" es la opción más elegida ${ }^{3}$. Además, en la mayoría de los casos, no se observó en las respuestas la mención al trabajo con nuevos géneros mediáticos. Al parecer, existiría una separación muy marcada entre aquellos considerados institucionales y válidos para ser enseñados y los que provienen de las nuevas tecnologías que son utilizados con mayor frecuencia en el ámbito familiar, privado y son menos estables y reglados. Si bien no es la postura que predomina, ya que son muchos los docentes que muestran preocupación por esta problemática e interés por implementar nuevas dinámicas, sabemos que la representación del discurso mediático y del uso de las nuevas tecnologías como un peligro 0 amenaza o como simples elementos de distracción o perturbación todavía sigue presente.

En cuanto a los relatos de experiencias didácticas, se limitan a búsqueda de información, producción de power points para exponer temas o bien lectura de diarios. En la mayoría de los casos se priorizó la enseñanza a través de los medios como vehículo o instrumento de información y conocimiento y no como fin en sí mismos. Entre las inquietudes que manifiestan, desde el punto de vista de los recursos y su accesibilidad, se repite la necesidad de que se garantice el acceso a internet y el funcionamiento eficaz de las netbooks entregadas en el marco del plan "Conectar igualdad" ción o capacitación, señalan no haber recibido formación específica acerca de educación en medios durante su carrera de grado, y solo un $17 \%$ menciona haber realizado capacitaciones posteriores. La mayoría de ellas orientadas al uso de herramientas tecnológicas. Asimismo, solicitan "mayor información actualizada y específica sobre el tema".

Para resumir y pensando en el desarrollo de nuestra propuesta, entre las conclusiones más relevantes, destacamos:

3 Entre las opciones se indicaba: "objeto de estudio en sí mismos", "fuentes de información", "tecnologías", "herramientas de comprensión y producción", "fuentes para trabajar cuestiones relativas al poder, ideología, manipulación”, "ejemplo para explicar cuestiones de gramática, normativa o textualidad", "material para analizar modos de vinculación de los jóvenes con los medios".

4 El programa estatal "Conectar Igualdad", creado en abril de 2010, tiene por objetivo entregar una netbook a estudiantes y docentes. Además, propone capacitar a los docentes en el uso de esta herramienta y elaborar propuestas para su incorporación en los procesos de enseñanza-aprendizaje. En la actualidad, sus efectos siguen en etapa de evaluación. 
- La escasa presencia verdaderamente significativa de los medios en las aulas. Se prioriza su papel como vehículos de información, dejando de lado su rol de actores sociales, políticos, su función de entretenimiento, de vínculo entre pares, entre otros.

- La necesidad de desarrollar actividades que se orienten al despliegue de estrategias relacionadas con la lectura mediática crítica.

- La inclusión no solo de géneros tradicionales sino también de nuevos géneros que tienen una presencia constante y relevante en la vida de jóvenes y adolescentes.

- El pedido por parte de los docentes de mayor formación teórica y metodológica.

En segundo lugar, desde el punto de vista teórico y metodológico, tenemos en cuenta las tres dimensiones que, desde el ACD, postula Fairclough $(1995,2008)$ para analizar un evento comunicativo:

1) Práctica textual: en este nivel la unidad de análisis es el texto. Se hace uso de teorías lingüísticas y se seleccionan las categorías relevantes para los propósitos de la investigación en los niveles sintáctico, léxico-semántico y pragmático. El análisis se enmarca en un nivel descriptivo en relación con las propiedades formales del texto.

2) Práctica discursiva: esta dimensión del análisis remite a los aspectos sociocognitivos de producción e interpretación de los textos. Se explica el modo como los participantes producen e interpretan los textos. El objetivo es relacionar el análisis con las prácticas discursivas e institucionales en las cuales se insertan. El análisis se enmarca en el nivel interpretativo con respecto a la relación texto e interacción.

3) Práctica social: este nivel considera las características de las estructuras sociales y culturales que enmarcan los eventos comunicativos en diferentes niveles: contexto de situación, institucional y social más amplio. Aquí surgen los conceptos de poder, ideología y hegemonía. El análisis se desarrolla en el nivel explicativo de la relación entre interacción y contexto social.

Consideramos que la sistematización de este investigador es una de las más operativas para servir como sostén de análisis de textos que posibiliten lecturas críticas de los mensajes mediáticos. Es una propuesta general que puede adaptarse a las características de textos multimodales y servir a modo de eje organizador de la instancia del 
análisis o de la instancia de la producción, y que debe adaptarse y especificarse según el tipo de género seleccionado.

\subsection{A modo de ejemplo}

Los estudiantes, orientados por el docente, pueden seleccionar un tema que despierte su interés y realizar un trabajo de búsqueda y selección de textos que hayan sido publicados en distintos formatos y con diversos propósitos. Consideramos fundamental organizar grupos de trabajo que permitan el aprovechamiento de la generación de vínculos intelectuales y afectivos a partir del intercambio de conocimiento, experiencia y valores. Algunos criterios que guíen la búsqueda podrían ser:

1) Focalizar en un problema social que los incluya — en mayor o menor gradocomo protagonistas y no solo como espectadores. En este sentido, los temas controvertidos que den lugar a opiniones encontradas y despierten polémica, al replicarse y extenderse rápidamente a través de géneros mediáticos nuevos y tradicionales posibilitan, en un primer momento, desarrollar estrategias de selección crítica teniendo en cuenta la calidad del producto mediático.

2) Elegir textos contrastantes en cuanto a forma, contenido y propósito comunicativo, que incentiven en los estudiantes su capacidad para establecer relaciones y determinar las limitaciones y potencialidades en cada caso.

Una vez seleccionados los textos, la primera dimensión del análisis que proponemos es descriptiva. Teniendo en cuenta el texto como unidad, especificamos aquellos recursos tecnológicos, léxicos, gramaticales, pragmáticos, usos del color, de los planos, distribución de objetos, matices de sonido, entre otros posibles, seleccionados de acuerdo con los efectos de sentido que pueden producir. El estudio implica realizar una caracterización formal y estructural según estilos y lenguajes propios de cada género. Las actividades desplegadas en este nivel se orientan al desarrollo de las dimensiones "lenguaje", "tecnología" y "estética" que forman parte de la competencia mediática.

La Tabla 1 resume las categorías y los interrogantes que estructuran la descripción y el análisis: 
Tabla 1. Dimensión descriptiva y sus categorías de análisis.

\begin{tabular}{|c|c|c|c|c|}
\hline Práctica & & $\begin{array}{c}\text { Análisis } \\
\text { (deconstrucción) }\end{array}$ & Categorías & $\begin{array}{c}\text { Competencia } \\
\text { mediática }\end{array}$ \\
\hline Textual & Descriptivo & $\begin{array}{l}\text { ¿Qué se dice?, } \\
\text { ¿acerca de qué?, } \\
\text { ¿cómo?, ¿con qué recursos?, } \\
\text { ¿qué códigos son utilizados?, } \\
\text { ¿qué argumentos son utilizados?, } \\
\text { ¿qué emociones se nombran o } \\
\text { reflejan? }\end{array}$ & $\begin{array}{l}\text { Lingüísticas, } \\
\text { visuales, auditivas, } \\
\text { gestuales, } \\
\text { espaciales }\end{array}$ & $\begin{array}{l}\text { Dimensión } \\
\text { "lenguaje", } \\
\text { "tecnología" y } \\
\text { "estética" }\end{array}$ \\
\hline
\end{tabular}

La segunda dimensión es interpretativa y considera el sentido de los recursos identificados y caracterizados cuando se utilizan y organizan con un propósito determinado. Cobran relevancia los presupuestos e inferencias y el concepto de estrategia discursiva enfatizado por muchos analistas críticos (Martin \& Van Dijk, 1998; Wodak, 2003; Pardo, 2007, 2012), que puede interpretarse como un modo de revelar el sistema de creencias del enunciador (Van Dijk, 1999b). De este modo se profundiza el análisis dejando de lado la descripción de los hechos para adentrarnos en los procedimientos discursivos que permiten enmarcar los contenidos en un determinado posicionamiento.

Siguiendo con nuestro ejemplo, en esta etapa del análisis cobra protagonismo el análisis contextual. Debemos considerar las instancias de enunciación o lugar de las condiciones de producción y la instancia de recepción o lugar de las condiciones de interpretación (Charaudeau, 2003). Lo importante es estimular a los estudiantes para que reflexionen acerca de la relevancia que adquiere el contexto a la hora de otorgar sentido a un texto, es decir, de las características propias del momento de producción, circulación y consumo. Podría indagarse acerca de aspectos económicos, fuentes de financiación, controles que se ejercen, fuentes de información, conformación del mapa de medios del país. Con respecto a las dimensiones que forman parte de la competencia mediática, se consideran en esta instancia las referidas a los "procesos de interacción", "de producción y difusión" y la dimensión "estética".

De acuerdo con los textos aportados por los grupos de trabajo, las preguntas orientadoras pueden ser: ¿qué características definen el momento de producción de los textos?, ¿por dónde circulan?, ¿a quiénes están destinados?, ¿quién o quiénes hablan?, ¿desde qué lugar?, ¿con qué propósito?, ¿quévoces se introducen?, ¿cómo son introducidas?, ¿cómo y quién regula el producto mediático?, ¿cuál es la opinión de la o las audiencias? Para contestarlas es importante fomentar el rol de los estudiantes como investigadores. Podrían realizar entrevistas a los trabajadores de los medios para interiorizarse acerca de su funcionamiento; también a moderadores de comentarios digitales o a los propios 
comentaristas, foristas, bloggers, etc. Asimismo, la aplicación de encuestas para conocer la reacción o las opiniones de las audiencias es un instrumento que puede enriquecer la investigación.

En la Tabla 2 presentamos las categorías que constituyen esta segunda dimensión del análisis:

Tabla 2. Dimensión interpretativa y sus categorías de análisis.

\begin{tabular}{|l|l|l|l|l|}
\hline \multicolumn{1}{|c|}{ Práctica } & \multicolumn{1}{|c|}{$\begin{array}{c}\text { Análisis } \\
\text { (deconstrucción) }\end{array}$} & \multicolumn{1}{|c|}{ Categorías } & \multicolumn{1}{|c|}{$\begin{array}{c}\text { Competencia } \\
\text { mediática }\end{array}$} \\
\hline Discursiva & Interpretativo & $\begin{array}{l}\text { iQué características definen el } \\
\text { momento de producción, circulación } \\
\text { y consumo de los textos?, ipor } \\
\text { dónde circulan?, ia quiénes están } \\
\text { destinados?, } \\
\text { iquién o quiénes hablan?, idesde qué } \\
\text { imagen? } \\
\text { icon qué propósito? } \\
\text { iqué voces se introducen?, icómo son } \\
\text { introducidas?, icómo y quién regula el } \\
\text { producto mediático? }\end{array}$ & $\begin{array}{l}\text { Categorías } \\
\text { discursivas } \\
\text { (implicaturas, } \\
\text { recursos } \\
\text { polifónicos, } \\
\text { estrategias) }\end{array}$ & $\begin{array}{l}\text { Dimensión } \\
\text { "procesos de } \\
\text { interacción", } \\
\text { "de producción } \\
\text { y difusión" y } \\
\text { "estética" }\end{array}$ \\
\hline
\end{tabular}

Por último, la dimensión explicativa busca esclarecer las relaciones entre las categorías discursivas analizadas y las características socioculturales más amplias que las definen y condicionan, así como dar cuenta del modo como estas participan en la definición de la estructura social. Aquí son relevantes los conceptos de poder, ideología y representaciones sociales que completan el análisis desde una perspectiva sociocognitiva y crítica. Las dimensiones "ideología y valores", propias de la competencia mediática, se concretan en esta etapa. La Tabla 3 muestra los interrogantes que guían el análisis y las categorías y dimensiones por considerar: 
Tabla 3. Dimensión explicativa y sus categorías de análisis

\begin{tabular}{|c|l|l|l|l|}
\hline \multicolumn{1}{|c|}{ Práctica } & \multicolumn{1}{|c|}{$\begin{array}{c}\text { Análisis } \\
\text { (deconstrucción) }\end{array}$} & \multicolumn{1}{c|}{ Categorías } & \multicolumn{1}{c|}{$\begin{array}{c}\text { Competencia } \\
\text { mediática }\end{array}$} \\
\hline Sociocultural & Explicativo & $\begin{array}{l}\text { ¿Qué intereses defienden los } \\
\text { enunciadores?, } \\
\text { ¿a quiénes representan?, } \\
\text { ¿qué sistemas de creencias es- } \\
\text { tán en juego?, } \\
\text { ¿qué representaciones se cons- } \\
\text { truyen?, } \\
\text { iqué relaciones de poder están } \\
\text { implicadas? }\end{array}$ & $\begin{array}{l}\text { Categorías } \\
\text { socioculturales y } \\
\text { cognitivas } \\
\text { (poder, ideología, } \\
\text { representaciones } \\
\text { sociales) }\end{array}$ & $\begin{array}{l}\text { Dimensión } \\
\text { "ideología y } \\
\text { valores" }\end{array}$ \\
& & & \\
\hline
\end{tabular}

Por supuesto que este modelo de análisis también contempla la producción de textos mediáticos. En un segundo momento, los estudiantes dejarán de ser analistas y de reflexionar sobre los productos mediáticos para transformarse en productores y creadores de sus propios textos. En la instancia de producción juega un rol predominante la capacidad de transformar significados existentes o producir otros nuevos haciendo uso de las categorías lingüísticas y discursivas, incentivando la creatividad y la sensibilidad estética y manejando, cuando sea necesario, herramientas comunicativas propias de entornos multimodales. Las estrategias por desplegar en esta instancia siguen sosteniéndose en los niveles descriptivos, interpretativos y explicativos.

En la etapa de producción, el trabajo permanente de reflexión y resolución del problema retórico es fundamental. Siguiendo con nuestro ejemplo, según el tema elegido puede producirse un texto cuyo propósito sea opinar, concientizar, informar, generar alternativas de solución de acuerdo con el problema social investigado. Cada grupo podría tener que ocuparse de un género en particular. Lo importante sería incluir géneros tradicionales y también los propios de las nuevas tecnologías. De esta manera, la producción de un video, una publicación de face, un folleto, se harán según los intereses de cada grupo y las características de la audiencia. Cabe destacar que más allá de cuál sea el género elegido, es imprescindible una clara definición de la situación retórica. "Acerca de qué", "para qué" y "a quién" son las preguntas básicas que los estudiantes deben plantearse y responder para adquirir gradualmente mayor autonomía a la hora de enfrentar el problema retórico, reflexionar sobre él, tomar decisiones y resolverlo.

Al evaluar las producciones, sería interesante que los diferentes grupos elaboraran una devolución del trabajo de sus compañeros destacando virtudes y cuestiones para mejorar, teniendo en cuenta las dimensiones descriptivas, interpretativas y explicativas. Como puede inferirse, la interacción, el diálogo, la colaboración entre pares siguen siendo 
protagonistas, más aún cuando se necesita que los escenarios pedagógicos incorporen las nuevas prácticas comunicativas como un espacio para compartir, interpelar, construir y transformar significados.

\section{Conclusión}

Hoy más que nunca leer y escribir implican un saber hacer, esto es, asumir roles, construir identidades, ejercer poder. El avance tecnológico no solo requiere sujetos con destrezas para el manejo técnico de las TIC sino, especialmente, ciudadanos capaces de gestionar su propio aprendizaje, de generar soluciones y nuevas ideas, de trabajar en colaboración y en interacción constante con otros, de manejar los afectos, teniendo en cuenta las características del género y de la situación retórica a la que deben responder. El debate acerca de los perjuicios o beneficios que traen los nuevos lenguajes, que a veces se resume en distorsión versus creatividad y economía, deja de tener sentido cuando comprendemos que el desarrollo del pensamiento crítico y creativo debe ser uno de los objetivos prioritarios por alcanzar en el trabajo en las aulas.

En este sentido, en el presente trabajo hemos procurado dar cuenta de algunos conceptos teóricos que despierten y guíen la reflexión en torno a la compleja relación entre educación y medios. Los conceptos desarrollados contribuyen a responder las preguntas acerca del por qué, para qué y cómo enseñar el discurso de los medios en la institución escolar. Creemos que, en muchos casos, el docente carece de una base teórica fuerte y sólida y se ve bombardeado — y hasta invadido - por nuevos estilos y formatos discursivos que implican un gran desafío a la hora de abordarlos en su práctica áulica. De ahí que hayamos diseñado una propuesta para el análisis y la producción de textos mediáticos que tuvo en cuenta, por un lado, un marco teórico general relativo a la educación en medios y, por otro, las representaciones de alumnos y docentes acerca de la problemática. Aspiramos a que nuestro aporte contribuya a orientar las prácticas pedagógicas hacia uno de los objetivos prioritarios que debe organizarlas teniendo en cuenta las características de las sociedades modernas: la formación de sujetos capaces de comprender significados mediáticos, tanto explícitos como implícitos, superficiales y subyacentes; y competentes para producir otros nuevos que reflejen originalidad, creatividad, actitud crítica y compromiso social. 


\section{Referencias}

Albaladejo, T. (2007). Creación neológica y retórica en la comunicación digital. En R. Sarmiento \& F. Vilches (eds.), Neologismos y sociedad del conocimiento (pp. 8189). Barcelona: Ariel.

Álvarez, L. \& Suárez, L.E. (2016). Análisis crítico del discurso en la apertura de los diálogos de paz en Colombia 2012. Cuadernos de Lingüística Hispánica, (28), 69-89. http://dx.doi. org/10.19053/0121053X.4909

Alvermann, D.E. \& Hagood, M.C. (2000). Critical Media Literacy: Research, Theory, and Practice in New Times. Journal of Educational Research, 93, 193-205.

Avendaño, G.S. (2016). La lectura crítica en Educación Básica Secundaria y Media: la voz de los docentes. Cuadernos de Lingüística Hispánica, (28), 207-232. http://dx.doi. org/10.19053/0121053X.4916

Beltrán, D. E. (2017). Redes sociales virtuales como dispositivos mediáticos contemporáneos. Cuadernos de Lingüística Hispánica, (30), 105-123. https://doi.org/10.19053/0121053X. $\mathrm{n} 30.0 .6190$

Berlanga, I. (2013). El discurso en los medios digitales. Principios de retórica clásica en las redes sociales. El caso Facebook. (Tesis doctoral). Universidad de Granada, Facultad de Comunicación y Documentación.

Buckingham, D. (2003). La educación en medios de comunicación y el fin del consumidor crítico. Monografías Virtuales, Ciudadanía, Democracia y Valores en Sociedades Plurales, (1). Recuperado de http://www.oei.es/valores2/monografias/monografia01/reflexion02.htm.

Buckingham, D. (2005). Educación en medios. Alfabetización, aprendizaje y cultura contemporánea. Barcelona: Paidós.

Cassany, D. \& Castellá, J. (2010). Aproximación a la literacidad crítica. Perspectiva, 28 (2), 353374.

Charaudeau, P. (2003). El discurso de la información. La construcción del espejo social. Barcelona: Gedisa.

De Fontcuberta, M. (2003). Medios de comunicación y gestión del conocimiento. Revista Iberoamericana de Educación, (32), 95-118.

De Fontcuberta, M. de \& Guerrero C. (2007). Una propuesta para la educación en medios. Cuadernos de Información, (20), 87-97. 
Dussel, I. (2011). La escuela y los nuevos medios digitales. Notas para pensar las relaciones con el saber en la era digital. En I. Dussel, V. Minzi et al. (comps.), La educación alterada. Aproximaciones a la escuela del siglo XXI. (pp. 9-28). Villa María: Eduvim.

Fairclough, N. (1995). Critical Discourse Analysis. London: Logman.

Fairclough, N. (2008). El análisis crítico del discurso y la mercantilización del discurso público: las universidades. Discurso y Sociedad, 2(1), 170-185.

Fairclough, N. \& Wodak, R. (2000). Análisis crítico del discurso. En Van Dijk, T. (comp). El discurso como interacción social. Estudios sobre el discurso: una introducción multidisciplinaria (pp. 367-404). Barcelona: Gedisa.

Ferrés, J. \& Piscitelli, A. (2012). La competencia mediática: propuesta articulada de dimensiones e indicadores. Comunicar, 19 (38), 75-82.

Flower, L. \& Hayes, J. (1981). A Cognitive Process Theory of Writing. College Composition and Communication, 32, 365-87.

Gálvez, M. (2005). La educación en medios en Iberoamérica: la visión de expertos. Comunicar, (24), 35-40.

García, F. (2010). Educación en medios ayer y hoy: tópicos, enfoques y horizontes. Magis, Revista Internacional de Investigación en Educación, 2(4), 279-298.

García, A., Seglem R. \& Share J. (2013). Transforming Teaching and Learning through Critical Media Literacy Pedagogy. Learning Landscapes, 6(2), 109-123.

Grasso, M., Pagola L. \& Zanotti, A. (2017). Políticas de inclusión digital en Argentina. Usos y apropiaciones dentro y fuera de la escuela. Pixel-Bit Revista de Medios y Educación, 50, 95-107.

Guerrero, I. \& Kalman, J. (2010) La inserción de la tecnología en el aula: estabilidad y procesos instituyentes en la práctica docente. Revista Brasileira de Educaçao, 15 (44), 213-229.

Hernández, N. (2014). La construcción mediática de perdedores y vencedores en el campo político: Análisis de las metáforas, tópicos y lexicalización. Cuadernos de Lingüística Hispánica, (25), 81-98.

Kress, G. \& Van Leeuwen, T. (2001).Multimodal Discourse. The Modes and Media of Contemporary Communication. London: Arnold.

Lankshear, C. \& Knobel, M. (2009) Nuevos alfabetismos. Su práctica cotidiana y su aprendizaje en el aula. Morata: Madrid. 
Luke, A. (2004). Two Takes on the Critical. In B. Norton \& K. Toohey (eds.), Critical Pedagogies and Language Learning (pp.21-29). Cambridge: Cambridge University Press.

Manghi, D. (2011). La perspectiva multimodal sobre la comunicación. Desafíos y aportes para la enseñanza en el aula. Diálogos Educativos, 22(11), 3-14.

Martín, J. (2003). Saberes hoy: diseminaciones, competencias y transversalidades. Revista Iberoamericana de Educación, (32), 17-34.

Martín, J. (2008). Estallido de los relatos y pluralización de las lecturas. Comunicar, 15(30), 15-20.

Martín,J. (2009). Cuando la tecnología deja de ser una ayuda didáctica para convertirse en mediación cultural. Teoría de la Educación. Educación y Cultura en la Sociedad de la Información, 10(1), 19-31. Recuperado de http://www.redalyc.org/articulo.oa?id=201018023002

Martín, L. \& Van Dijk, T. (1998). Había un problema y se ha solucionado. La legitimación de la expulsión de inmigrantes 'ilegales' en el discurso parlamentario español. En L. Martín \& R. Whittaker (eds.), Poder-decir o el poder de los discursos (pp. 169-234). Madrid: Arrecife.

Masterman, L. (1993). La enseñanza de los medios de comunicación. Madrid: La Torre.

Morduchowicz, R. (2009). Cuando la educación en medios es política de Estado. Comunicar, 16(32), 131-138.

Pardo, N. (2007). Cómo hacer análisis crítico del discurso. Chile: Frasis.

Pardo, N. (2012). Análisis crítico del discurso: conceptualización y desarrollo. Cuadernos de Lingüística Hispánica, (19), 41-62.

Perelman Ch. \& Olbrechts-Tyteca (1994) Tratado de la argumentación. La nueva Retórica. Madrid: Gredos.

Pérez, J.M. (2005) Hacia un nuevo concepto de educación en medios. Comunicar, (24), 21-24.

Pérez, M.A. \& Delgado, A. (2012). De la competencia digital y audiovisual a la competencia mediática: dimensiones e indicadores. Comunicar, 20(39), 25-34.

Pujolá, J. T., García, M. A. et al. (2009): Textos generados en la web 2.0. En M. A. Penas \& R. González (eds.), Estudios sobre el texto. Nuevos enfoques y propuestas (pp. 279-299). Frankfurt am Main: Peter Lang.

Román, M. \& Murillo, J. (2014). Disponibilidad y uso de TIC en escuelas latinoamericanas: incidencia en el rendimiento escolar. Educ. Pesqui, 40(4), 869- 895. 
Romano, M.B. (2015). Ciudadanos indignados: Argumentación y emoción en comentarios digitales de lectores. RILL Nueva época. Revista del Instituto de Investigaciones Lingüísticas y Literarias Hispanoamericanas, (20), 133-148.

Romano, M.B. (2017). Educación y medios en la escuela secundaria argentina: la mirada de los estudiantes. Revista Actualidades Investigativas en Educación, 17(3), 1-33. http://dx.doi. org/10.15517/aie.v17i3.29109

Rowsell, J. \& Walsh, M. (2015). Repensar la lectoescritura para nuevos tiempos: multimodalidad, multiliteracidades y nuevas alfabetizaciones. Enunciación, 20 (1), 141-150.

Sal, J.C. (2013) Comentario digital: género medular de las prácticas discursivas de la cibercultura. Caracteres. Estudios Culturales y Críticos de la Esfera Digital, 2 (2), 152-171.

Serna, J. \& Díaz, J. (2014). Propuesta didáctica para la comprensión crítica en la Universidad La Gran Colombia. Cuadernos de Lingüística Hispánica, (25), 165-180.

Sunkel, G. \& Trucco, D. (2014). Las tecnologías digitales en las escuelas de América Latina. Visión panorámica. Versión. Estudios de Comunicación y Política, 34, 21-38.

Tirado, R., \& Aguaded, I. (2014). Influencias de las creencias del profesorado sobre el uso de la tecnología en el aula. Revista de Educación, (363), 230-255.

Vacchieri, A. (2013). Las políticas TIC en los sistemas educativos de América Latina: caso Argentina. Buenos Aires: Unicef.

Van Dijk, T. (1999a). El análisis crítico del discurso. Anthropos, (186), 23-36.

Van Dijk, T. (1999b). Ideología. Una aproximación multidisciplinaria. Barcelona: Gedisa.

Van Dijk, T. (2003). La multidisciplinariedad del análisis crítico del discurso: un alegato a favor de la diversidad. En R. Fairclough \& M. Meyer (eds.) Métodos de análisis crítico del discurso (pp. 143-176). Barcelona: Gedisa.

Wilson, C., Grizzle, A., Tuazon, R., Akyempong, K. \& Cheung, C. (2011). Alfabetización mediática e informacional. Currículum para profesores. París: Unesco.

Wodak, R. (2003). El enfoque histórico del discurso. En R. Wodak \& M. Meyer (eds.) Métodos de análisis crítico del discurso (pp. 101-141). Barcelona: Gedisa. 